\title{
RESUMO
}

\section{ACONSTITUCIONALIDADE DAS INTERPRETACÕES DO SUPREMO TRIBUNAL FEDERAL: UMA ANÁLISE ACERCA DA PRISÃO EM SEGUNDA INSTÂNCIA}

CONSTITUTIONALITY OF SUPREMO TRIBUNAL FEDERAL INTERPRETATIONS: AN ANALYSIS ABOUT SECOND INSTANCE

CONSTITUCIONALIDAD DE LAS INTERPRETACIONES DEL SUPREMO TRIBUNAL FEDERAL: ANÁLISIS SOBRE LA PRISIÓN TRAS SEGUNDA INSTANCIA
O estudo foi realizado a partir de análise acerca da constitucionalidade das decisões do Supremo Tribunal Federal (STF), acerca da prisão em segunda instância. Além disso, se verificou o quanto decisões como a analisada podem refletir no que diz respeito a concretização de precedentes, que podem nortear todo o ordenamento jurídico. Se ponderou a respeito do novo posicionamento acerca do tema, bem como sua compatibilidade com o disposto no artigo $5^{\circ}$, LVII, do Texto Maior. A pesquisa é de cunho bibliográfico, com a utilização do método indutivo.

\section{PALAVRAS-CHAVE}

Instabilidade. Insegurança Jurídica. Decisões do STF. 


\section{ABSTRACT}

The study was conducted based on an analysis of the constitutionality of the decisions of the Supreme Court, about the arrest in the second instance. In addition, it was verified how much decisions such as the one analyzed may reflect with regard to the setting of precedents, which may guide the entire legal system. Consideration was given to the new position on the subject, as well as its compatibility with the provisions of article 5, LVII, of the Larger Text. The research is of bibliographic nature, using the inductive method.

\section{KEYWORDS}

Instability. Juridical Insecurity. Supreme Court Decisions.

\section{RESUMEN}

El estudio se realizó sobre la base de un análisis de la constitucionalidad de las decisiones de la Corte Suprema sobre la prisión tras condena en segunda instancia. Además, se verificó cuántas decisiones, como la analizada, pueden reflejar con respecto al establecimiento de precedentes, lo que puede guiar a todo el sistema legal. Se consideró la nueva posición sobre el tema, así como su compatibilidad con las disposiciones del artículo 5, LVII, de la Constitución. La investigación es de naturaleza bibliográfica, utilizando el método inductivo.

\section{PALABRAS CLAVE}

Inestabilidad. Inseguridad jurídica. Decisiones de STF. 


\section{INTRODUÇ̧̃̃o}

A Constituição Federal de 1988 atribuiu ao Supremo Tribunal Federal (STF) a função fundamental de resguardar os preceitos normativos e conferir a última palavra acerca da compatibilização das normas infraconstitucionais com o seu texto.

As decisões da Corte devem estar pautadas na legislação e somente em situações extraordinárias a partir de entendimentos dos Ministros, sob pena de haver conflito e interferência entre os poderes, tendo em vista que estas precisam ser as mais imparciais possíveis, não devendo ser analisada no prisma de quem é o indivíduo ali julgado, a fim de que os ditames constitucionais como a efetivação da justiça sejam respeitados.

O assunto tratado no presente trabalho está situado na matéria de Direito Constitucional com um paralelo ao Direito Penal em que tratamos da constitucionalidade das interpretações do Supremo Tribunal Federal, com enfoque na temática da prisão em segunda instância, em que se almeja responder alguns questionamentos, dentre os quais: até que ponto as interpretações podem mudar preceitos normativos constitucionais expressos? Qual a função do STF? A decisão acerca da prisão em segunda instância é constitucional?

0 método adotado foi o indutivo, sendo realizada pesquisa qualitativa de revisão bibliográfica.

\section{A CONSTITUIÇÃO FEDERAL DE 1988}

A Constituição Federal tem representado uma infinidade de conquistas de cunho histórico, jurídico e cultural, após uma grande evolução, principalmente com a queda do regime militar, período crítico em que o país passou entre 1964 a 1985 aonde vários direitos e garantias foram restringidos à sociedade. A Constituição Federal de 1988 restabeleceu a democracia e vários direitos que haviam sido desconsiderados durante a ditadura militar, tais como: Liberdade Política, Liberdade de Imprensa, Garantia dos Direitos Individuais, equilíbrio de poder entre Executivo, Legislativo e Judiciário, desta forma a constituição passa a ter uma importância relevante para a sociedade, além de ser superior a qualquer outra norma vigente no País.

Nesse diapasão, afirma Lenza (2015) que a Constituição Federal passou a ter maior relevância, assumindo um viés democrático, bem como uma carga valorativa de maior relevância, orientando todo o ordenamento jurídico.

No mesmo sentido leciona Alexandre de Morais (2006) que o direito constitucional traz a organização e funcionamento do Estado, estabelecendo sua estrutura e organização de instituições e órgãos como um todo, limitando o poder e estabelecendo direitos e garantias fundamentais.

Dessa forma, há o controle de constitucionalidade, que garante que leis e atos normativos estejam de acordo com os preceitos do Texto Maior, estabelecendo um Estado Democrático de Direito. Insta salientar que a ideia de um controle de constitucionalidade somente é possível a partir do reconhecimento da supremacia da Constituição Federal. 
Podemos verificar que o ordenamento jurídico é um sistema, que pressupõe uma unidade, devendo estar em harmonia e caso isso não ocorra deve-se buscar mecanismos de correção, destinada a restabelecer a harmonia. Nesse contexto o controle de constitucionalidade é um desses mecanismos, sendo ele um dos mais importantes, em que se verifica a compatibilização ente uma lei ou ato normativo infraconstitucional, base nas diretrizes da constituição federal.

Conforme esclarece Costa, Carvalho, Farias (2016), desde meados dos anos 60 tem acontecido uma concentração de competências ao STF, tanto é que a Constituição de 1988 ampliou o rol de legitimados para a propositura de ações no controle concentrado de constitucionalidade, que antigamente cabia apenas ao Procurador-Geral de República, além disso, foram criadas as ações de Arguição de Descumprimento de Preceito Fundamental e a Ação Declaratória de Constitucionalidade, além de remédios constitucionais como o Mandado de Injunção, ou ainda a Reclamação Constitucional, possíveis pela via incidental.

Nesse sentido, com bastante propriedade, estabelece o artigo 27 da Lei n 9.868/99:

Art. 27. Ao declarar a inconstitucionalidade de lei ou ato normativo, e tendo em vista razões de segurança jurídica ou de excepcional interesse social, poderá o Supremo Tribunal Federal, por maioria de dois terços de seus membros, restringir os efeitos daquela declaração ou decidir que ela só tenha eficácia a partir de seu trânsito em julgado ou de outro momento que venha a ser fixado.

Portanto, o legislador constituinte brasileiro, tentando manter harmônica e independente a relação entre esses três poderes e, além disso, preocupado com a possibilidade de abuso de poder, determinou, no texto constitucional, as funções a ser desempenhada por cada um desses entes, erigido essa decisão ao status de cláusula pétrea (CRFB/88, art. 60, § $\left.4^{\circ}, \mathrm{III}\right)$.

A Constituição Federal de 1988 veio assegurar a sociedade direitos e garantias, junto com essa reforma, também adveio às cláusulas pétreas. Pois bem, o que seriam essas Cláusulas Pétreas?

As cláusulas pétreas são dispositivas que impõem à sociedade determinados preceitos irremovíveis, isso porque tendo como paradigma o significado da palavra Cláusula Pétrea, temos como resultado "duro como pedra”, sendo assim, causasse uma limitação quanto à possibilidade de alteração, impossibilitando assim que o legislador venha remover ou abolir determinadas matérias.

Nesse mesmo raciocínio traz o ensinamento de Bulos (1999), que afirma que a expressão "pétrea" advém da palavra "pedra”, por significar aquilo que é duro, difícil de ser alterado, assim, no campo constitucional, tais cláusulas não podem ser abolidas pelo Poder Constituinte derivado. Tais medidas, ao serem adotadas, visavam evitar que assuntos de grande relevância pudessem ser precipitadamente alterados.

Conforme entendimento de vários doutrinadores entre eles Lenza (2015), as cláusulas pétreas não são somente as elencadas pelo artigo $5^{\circ}$ da Constituição Federal, deste modo ele é mais exemplificativo do que taxativo, entretanto, pois estes não excluem outros decorrentes dos regimes ou princípios adotados, bem como os Tratados Internacionais que o país faz parte.

Vejamos o que diz Boff (2013), acerca do tema em contento, uma vez que afirma que a Federação é o ponto de sustentação do Estado e representa limites materiais para a reforma, tendo em vista que 
se reforçou a ideia de autonomia entre os entes federados, sendo que, com a atual Constituição, entes federados viram suas competências modificadas, muitas das quais ampliadas, posto que são capazes de se auto organizar, autogovernar e autoadministrar.

Dessa forma, segundo o autor, que utiliza do ensinamento de Ivo Dantas, a divisão de poderes é uma maneira de garantir que a forma federativa que foi adotada pela Constituição Federal de 1988, seja respeitada e observada, para que certas decisões não possam ser usadas de forma diversa, da proposta, com intuito de modificar preceitos normativos de grande relevância a sociedade.

Nessas considerações, uma proposta de emenda não precisa trazer propriamente uma ameaça eminente aos princípios por ela defendidos e assegurados, basta uma tendência de abolição de qualquer preceito do artigo 60 , parágrafo $4 .^{\circ}$, para que não possa, nem ao menos, ser proposta.

Ante exposto, podemos afirmar que o posicionamento da Assembleia Constituinte ao tornar os princípios constantes na Constituição como supremas, foi de inteira importância, pois ela é um meio e nunca um fim em si mesma. Os preceitos constitucionais servem para ordenar a realidade circundante, todavia, as interpretações que lhes atribuam devem ser realizadas de acordo com os valores democráticos, sendo a nossa Magna Carta o enfoque, pois qualquer ato ou interpretação que desconstrua preceitos constitucionais claros e precisos seria uma afronta ou uma forma de reescrever a norma jurídica.

\section{SUPREMO TRIBUNAL FEDERAL E SUA FUNÇÃO FUNDAMENTAL}

Explana Luiz Fux (2018) que o STF teve suas origens em 1808, quando a família real portuguesa se mudou para o Brasil, por meio da Casa de Suplicação, que se concretizou com o Alvará Régio, sendo que as funções da instituição eram basicamente o julgamento de forma definitiva e em última instância de litígios. Mais adiante, em 1828, o Supremo Tribunal de Justiça foi criado, na vigência da primeira Constituição brasileira, de 1824 e substituiu a Casa de Suplicação, sendo que a Corte iniciou os trabalhos com forte influência portuguesa, apesar de a Independência já ter ocorrido há alguns anos. Os magistrados eram tratados como nobres e totalizavam 17 membros.

Somente em 1890, com o Decreto 848/1890 que a Corte passou a ser denominada Supremo Tribunal Federal, a partir de influências da Corte americana. O Tribunal passou a ser composto por 15 membros vitalícios, nomeados pelo Presidente da República.

Muitas mudanças estruturais, políticas e econômicas ocorreram no país desde a criação do STF, sendo que a formação atual tem sua previsão na Constituição de 1988, em seu artigo 101, sendo composto por 11 Ministros, que são divididos em duas Turmas, com cinco membros cada. 0 Presidente do STF participa apenas de sessões plenárias. A nomeação dos Ministros é de livre escolha do Presidente da República, após aprovação do indicado por maioria absoluta do Senado Federal (LENZA, 2015).

Além dessa reorganização, foi também passado a este órgão uma posição de guardião e defensor da Constituição, a fim de que fosse possível defender e assegurar a efetivação dos direitos fundamentais que constam no Texto Maior e diante de tal fato, a competência do STF foi ampliada, dentre as quais a possibilidade de julgar Ações no Controle de Constitucionalidade, que inclui leis e atos 
normativos emanados dos Poderes Legislativo e Judiciário, embora seus membros não sejam eleitos pelo povo, como ocorre entre os exercentes de cargos políticos (FUX, 2018).

Nessa mesma linha, foi argumento utilizado pelo Ministro Celso de Mello relator da Ação Direta de Inconstitucionalidade 3.345 e 3.365, onde indeferiram o pedido de liminar (HC 86522).

Assim, o Supremo Tribunal Federal, é o órgão máximo do Poder Judiciário, que tem competência de processar e julgar, originariamente o habeas corpus $(\mathrm{HC})$, o mandado de injunção, as infrações penais comuns, em que o Presidente da República, o Vice-presidente, os membros do Congresso Nacional, seus próprios Ministros e o Procurador-Geral da República estejam envolvidos; entretanto, sua maior finalidade é o Controle Concentrado de Constitucionalidade, ou seja, somente a Corte pode processar e julgar Ações Diretas de Inconstitucionalidade, genéricas ou interventivas, as Ações de Inconstitucionalidade por Omissão e as Ações Declaratórias de Constitucionalidade, com o intuito de garantir a prevalência das normas constitucionais no ordenamento jurídico.

O STF, sendo Guardião da Constituição, acolheu a teoria dos freios e contrapesos para limitar os atos praticados em excesso pelos organismos que compõem a Unidade Federativa do Brasil, na ADI 293-7/600.

Cumpre advertir que as normas constitucionais devem ser compatíveis com o espírito constitucional e cabe ao STF, como mostrado na ADI 293, a função de analisar a compatibilidade das normas frente aos preceitos estabelecidos em sua obra primária; caso a aplicação de normas infraconstitucionais seja sem a observância da Lei Suprema do Estado, considera-se inválida.

Então cabe ao Supremo Tribunal Federal, tomar providências e decidir em consonância com o espírito da Constituição, garantindo a todos aqueles que tiverem seus direitos fundamentais ameaçados ou até mesmo aqueles que venham por ação ou omissão transgredir direito alheio o devido julgamento.

\section{REGRAS E PRINCÍPIOS CONSTITUCIONAIS}

O ordenamento jurídico brasileiro é dotado de regras, assim como princípios, sendo capazes de prescrever condutas que, quando houver transgressão, será considerada como ato de desobediência a preceitos normativos, ou seja, antijurídicos.

Os princípios são aqueles pautados em uma generalidade, constituídos como uma regra mais geral, pois comporta uma série indeterminada de aplicação, sendo usado em casos concretos na medida do possível. Assim, ao ocorrer um conflito de princípios, a antinomia se resolverá a partir de um processo de ponderação, também chamado de sopesamento, por meio do qual se verificará, por uma análise de peso, qual princípio deve produzir efeitos no caso concreto, sendo importante lembrar que o princípio que se sobressair não eliminará o outro do ordenamento como ocorre com as regras, podendo vir a prevalecer sobre o princípio colidente se as circunstâncias do caso se modificarem (ALEXY, 2015).

Já a regra, conforme teoria de Dworkin (2007), estas são como “tudo ou nada”, pois ela é feita para aplicação em casos específicos, devendo ser aplicada em sua totalidade ao caso concreto, sendo que quando duas regras colidirem, a lei especial derrogará a lei geral, a lei posterior afastará a anterior. 
Podemos então observar que as regras fixam direitos e deveres definitivos, devendo sempre ser aplicada na sua totalidade e quando houver um conflito entre elas, uma deixará de existir, pois ao reconhecer uma delas, a outra se torna automaticamente inválida; enquanto os princípios estabelecem direitos e deveres que devem ser interpretados juridicamente em delimitação ao alcance da norma, onde será tirada a sua essência e aplicado ao caso concreto, de forma racional e razoável; quando ocorrer hipóteses de incidência, não há certeza de que aquilo que determinam ocorrerá, visto que outro princípio pode apresentar um maior peso naquele caso específico, por esse motivo um não deixará de existir, pois apenas foi ponderado no caso em contendo.

Outro ponto que também é importante ressaltar é que os princípios são independentes, entretanto, para que se torne um princípio eficaz, se faz necessária à imposição de uma regra, pois eles existem para dar força. Sendo assim, tanto as regras como os princípios são normativas autoaplicáveis, as quais possuem características distintas, mas a relação é de complementariedade, uma vez que as regras pavimentam o caminho de aplicação dos princípios.

Assim, quando há colisão entre princípios, se busca a análise do caso concreto e se um é mais específico ao caso do que outro, conforme os dizeres de Alexy (2015, p. 93): "Se dois princípios colidem - o que ocorre, por exemplo, quando algo é proibido por um princípio e, de acordo com outro, permitido -, um dos princípios terá que ceder".

O conflito entre duas regras, uma será excluída, fazendo com que a mais específica ou atual prevaleça, nesse ínterim, feitas todas essas considerações vale frisar que não existem princípios absolutos, nem regras absolutas, pois todos encontram limites em outros princípios também consagrados no texto constitucional.

Por mais importante que o princípio ou regra seja, estes não podem ser considerados absolutos porque, se algum for de encontro a algum preceito constitucional deve ser considerado inválido, uma vez que, conforme já mencionado, violar as normas constitucionais, a sua essência, seria como uma ruptura da Constituição.

\section{PRESUNÇÃO DE INOCÊNCIA}

O princípio da presunção de inocência ou não culpabilidade, está expresso na Carta Maior, no artigo $5^{\circ}$, inciso LVII, que estabelece "ninguém será considerado culpado até o trânsito em julgado de sentença penal condenatória”.

Mas o que seria essa presunção? O significado de presunção, segundo dicionário (GOOGLE, on-line), é o ato de presumir baseado em indícios, suposição que se tem por verdadeira, sendo assim presunção de inocência, seria um ato onde se presume a inocência de alguém até que se prove o contrário.

Em uma análise mais atentada ao artigo, surge uma dúvida: o dispositivo em comento contém um princípio ou uma regra? Verifica-se nesse caso que o artigo $5^{\circ}$, LVII, CF, na sua interpretação literal é possível extrair a seguinte norma ou regra: É proibido que se considere alguém culpado até o trânsito em julgado de sentença penal condenatória. 
Desta forma, podemos verificar que o artigo condiciona o elemento culpa ao trânsito em julgado de sentença penal condenatória, assim, não tem como se considerar alguém penalmente culpado de algo que ainda há possibilidade do ônus da prova, podendo este, recorrer de decisão condenatória, o que significa que a sentença ainda não transitou em julgado, logo pode-se compreender que, se esse indivíduo não pode ser considerado culpado então ele é, juridicamente, inocente, portanto, não lhe pode ser imposta uma pena de prisão, exceto as exceções previstas no artigo $5^{\circ}$, inciso LXI, da Constituição Federal, sendo elas as prisões cautelares.

Diante disso, podemos entender, que, para o nosso ordenamento jurídico o que se estampa no artigo $1^{\circ}$, III, da Constituição Federal, é dever do Estado respeitar a dignidade da pessoa humana, por esse motivo, o ser humano nasce inocente e assim deve permanecer até que o Estado, por seu trâmite judicial, consiga provar a sua culpa, na qual somente se daria por meio de uma sentença, em que não mais fosse possível recurso.

Desta forma, é possível também considerar que a prisão cautelar seria uma prisão processual, em que o Estado possa garantir que o processo seja conduzido de forma correta, impedindo assim que o acusado venha produzir provas indevidas, coagir testemunhas ou até mesmo tente fugir, para se imunizar da aplicação da lei penal.

Assim, a prisão processual e a prisão-pena são distintas, sendo que a primeira tenta impedir que o acusado perturbe o decorrer da investigação ou que este venha a fugir, desta forma, esta serve para garantir a condução do processo, a segunda, por sua vez é a forma de início do pagamento da pena imposta, após ser comprovada a culpa.

A presunção de inocência não está prevista somente no ordenamento jurídico brasileiro, vários outros ordenamentos preveem uma forma de declaração final de culpa, mesmo que estas sejam diversas, o fim, se distingue. Temos como exemplo os artigos $7^{\circ}$ ao $9^{\circ}$, da Declaração dos Direitos do Homem e do Cidadão (DECLARAÇÃO..., 1973).

Já a Declaração Universal dos Direitos Humanos, prevê em seu artigo 11 que: “Todo ser humano acusado de um ato delituoso tem o direito de ser presumido inocente até que a sua culpabilidade tenha sido provada de acordo com a lei, em julgamento público no qual lhe tenham sido asseguradas todas as garantias necessárias à sua defesa” (DECLARAÇÃO..., 1948).

A definição do que seria o trânsito em julgado não foi expressa no ordenamento jurídico brasileiro, o que levou, os doutrinadores a fixar um conceito, sendo possível entender que a coisa transitada em julgado, seria o esgotamento total de todos os recursos possíveis, isso porque, caso o indivíduo seja colocado para realizar o cumprimento da pena, antes de ter sido considerado, sem sombra de dúvidas culpado, seria colocado à beira da injustiça.

E, conforme diz o Ministro Cezar Peluso, "não há nada nem ninguém neste mundo que consiga, após o reconhecimento definitivo da inocência daquele que foi objeto da restrição ou da perda de liberdade no curso de processo pena, repor-lhe a integridade pessoal ao estado anterior, quando absolvido" (Min. Cezar Peluso, HC 84.078/MG, p. 1.128).

Contudo, a questão é eivada de muita discussão e com frequência é objeto de decisão do STF, como se verá adiante, ao se analisar algumas das decisões da Corte acerca da temática. 


\subsection{ALGUNS DOS POSICIONAMENTOS DO STF NOS ÚLTIMOS DEZ ANOS}

Em 2009, o STF julgou o HC 84.078, uma vez que um indivíduo que havia sido condenado em um Júri interpôs o HC em substituição ao Recurso Ordinário, uma vez que o Ministério Público havia solicitado sua prisão, posto que estava dissipando bens e havia receio de fuga. O Ministro Eros Grau, relator do então recurso, em seu voto afastou o fundamento de prisão preventiva, alegando que o encarceramento do paciente após julgamento de recurso de apelação ganha contornos de execução antecipada da pena e não de prisão preventiva.

Em análise ao artigo 637 do Código de Processo Penal reconhece que não tem efeito suspensivo, entretanto que a Lei $n^{0} 7.210 / 1984$ condicionou a execução da pena restritiva de direitos ao trânsito em julgado e que ao ser promulgada a Constituição de 1988 definiu, em seu artigo $5^{\circ}$, inciso LVII, que “ninguém será considerado culpado até o trânsito em julgado da sentença condenatória" (STF, 2009).

Nessa seara, a conclusão a que se chegou à época é que a Lei de Execução Penal não poderia ser aplicada, uma vez que para se executar uma sentença, era preciso que esta já tivesse transitado em julgado, ficando a ementa do acórdão da seguinte forma:

HABEAS CORPUS. INCONSTITUCIONALIDADE DA CHAMADA "EXECUÇÃO ANTECIPADA DA PENA". ART. $5^{\circ}$, LVII, DA CONSTITUIÇÃO DO BRASIL. DIGNIDADE DA PESSOA HUMANA. ART. $1^{\circ}$, III, DA CONSTITUIÇÃO DO BRASIL. 1. 0 art. 637 do CPP estabelece que "[0] recurso extraordinário não tem efeito suspensivo, e uma vez arrazoados pelo recorrido os autos do traslado, os originais baixarão à primeira instância para a execução da sentença". A Lei de Execução Penal condicionou a execução da pena privativa de liberdade ao trânsito em julgado da sentença condenatória. A Constituição do Brasil de 1988 definiu, em seu art. $5^{\circ}$, inciso LVII, que "ninguém será considerado culpado até o trânsito em julgado de sentença penal condenatória”. 2. Daí que os preceitos veiculados pela Lei n. 7.210/84, além de adequados à ordem constitucional vigente, sobrepõem-se, temporal e materialmente, ao disposto no art. 637 do CPP.3. A prisão antes do trânsito em julgado da condenação somente pode ser decretada a título cautelar.

4. A ampla defesa, não se a pode visualizar de modo restrito. Engloba todas as fases processuais, inclusive as recursais de natureza extraordinária. Por isso a execução da sentença após o julgamento do recurso de apelação significa, também, restrição do direito de defesa, caracterizando desequilíbrio entre a pretensão estatal de aplicar a pena e o direito, do acusado, de elidir essa pretensão. (ST, Pleno, HC 84.078, Tel. Min. Eros Grau, j. 05/02/2009).

Nessa decisão, o Supremo Tribunal Federal, enalteceu os ditames da Lei Maior, respeitando a preceito normativo Constitucional da presunção de inocência, assegurada no artigo 5 , LVII, CF/88.

Anos mais tarde, em 2016, ocorreu o julgamento do HC 126.292, questionando novamente a possibilidade ou não do início do cumprimento de pena após a confirmação de sentença pela Segunda Instância (STF, 2016).

Diante da situação pela qual o país passava, incluindo investigações e escândalos de corrupção, além de instabilidade econômica e política, após analisar o mérito, o STF mudou seu entendimento, 
justificando que a presunção de inocência até o trânsito em julgado da sentença estava permitindo a interposição de inúmeros recursos, com a finalidade de retardar ou mesmo impedir o início do cumprimento da pena. Nesse sentido vejamos a decisão da Suprema Corte:

Ementa: PROCESSUAL PENAL. EMBARGOS DE DECLARAÇÃO. VÍCIOS DO ART. 619 DO CÓDIGO DE PROCESSO PENAL. INEXISTÊNCIA. 1. Segundo o acórdão embargado, “a execução provisória de acórdão penal condenatório proferido em grau de apelação, ainda que sujeito a recurso especial ou extraordinário, não compromete o princípio constitucional da presunção de inocência afirmado pelo artigo $5^{\circ}$, inciso LVII da Constituição Federal." 2. De acordo com o estatuído no artigo 619 do CPP, os embargos de declaração são cabíveis nas hipóteses de ambiguidade, obscuridade, contradição ou omissão. No caso, não se verifica a existência de quaisquer desses vícios. 3. Embargos de declaração rejeitados.

Um dos fundamentos usados no julgamento se refere ao fato de que em muitos países o cumprimento provisório da pena tem início antes do trânsito em julgado da sentença, a fim de evitar a prescrição e a impunidade. Na mesma oportunidade foi entendido que a presunção de inocência é um princípio e, como tal, pode ser relativizado.

Contudo, no ano de 2019 aconteceu novo julgamento acerca da temática, por meio das Ações declaratórias de constitucionalidade (ADC) 43, 44 e 54 e, com um placar apertado de 6 votos a 5, a Corte Suprema mais uma vez muda seu entendimento e proíbe o cumprimento da pena antes do trânsito em julgado da sentença (MIGALHAS, 2020).

Insta salientar, a partir da análise dos três casos em que a temática da prisão após condenação em Segunda Instância esteve em pauta no STF, o que pode concluir é que ainda há muitas dúvidas acerca do que é de fato considerado justo nessa seara e, dependendo da formação da Corte, a decisão tende a ser revista, posto que é impossível que os julgadores não se deixem influenciar pela realidade do país no momento do julgamento.

A presunção de inocência é tema debatido e assegurado em vários ordenamentos jurídicos, principalmente nas normas de Direito Internacional, temos como exemplos: Declaração Universal dos Direitos do Homem e do Cidadão, o Pacto Internacional dos Direitos Civis e Políticos, a Convenção Americana de Direitos Humanos, entre outros, mas o que se busca em todas elas é a integridade pessoal da pessoa humana, pois após este ser inocentado de ação penal na qual já lhe foi imposta medida de cumprimento de pena antecipado, não a como reverter o dano a integridade física, moral e intelectual causada àquele cidadão.

Contudo, é essencial que a Corte estabeleça um precedente e mantenha tal decisão ao menos por alguns anos, a fim de que o entendimento possa ser concretizado.

Além disso, é essencial se analisar a realidade brasileira, uma vez que a população carcerária é bastante grande e as condições nas prisões, em sua maioria, são deploráveis (CONJUR, 2019).

Dessa forma, é preciso analisar cada caso, e, uma vez que haja risco de a pena se tornar inútil no futuro, que seja iniciada antes do trânsito em julgado, principalmente quando envolver crimes mais graves. Porém, em casos menos graves, seria aconselhável o trânsito em julgado, ou ainda penas eficientes, mas diferentes da prisão. 


\section{CONCLUSÃO}

Após analisar as últimas decisões do STF, envolvendo a temática da prisão em Segunda Instância, o que se pode concluir é que o que tem prevalecido no país é a instabilidade das decisões, que mal podem ser consideradas precedentes, tendo em vista que poucos anos depois de a Corte Suprema estabelecer um entendimento sobre o assunto, é chamada a decidir novamente, podendo alterar tal entendimento.

Tal medida tem gerado insegurança jurídica, uma vez que o indivíduo que está sendo julgado por um crime em que caiba a pena privativa de liberdade não sabe se terá o direito de responder o processo em liberdade, até o trânsito em julgado da sentença ou se poderá ser preso após a confirmação da sentença pela Segunda Instância, posto que o entendimento do STF pode ser alterado, até que o processo finde.

Instabilidade e insegurança jurídica podem ser extremamente prejudiciais para uma democracia, tendo em vista que, dependendo de quem ou o que está sendo julgado, a decisão é de forma diferente.

Os julgamentos devem ser eivados da imparcialidade e da justiça, dessa forma, é preciso que as decisões do Poder Judiciário, em especial da Corte Suprema sejam respeitados, ao menos por um tempo razoável e que as decisões sejam pautadas na realidade brasileira.

As prisões no país estão superlotadas e as condições disponíveis em sua maioria não são das melhores, contudo, o sentimento de impunidade pode ocasionar uma série de problemas, dentre os quais incentivar e encorajar o cometimento de crimes.

Assim, seria interessante que a prisão após condenação em Segunda Instância pudesse ser analisada a partir da realidade do caso concreto e, em casos específicos, ser possível sim a prisão antes do trânsito em julgado, em especial quando houver suspeitas de má-fé, como possibilidade de fuga, interposição de recursos infundados, a fim de retardar o cumprimento da pena, entre outros.

A prisão também pode ser necessária antes da decisão final em casos, envolvendo crimes graves, como os crimes hediondos.

Por outro lado, quando se tratar de crimes de menor potencial ofensivo, penas como o incentivo ao emprego e educação podem ser muito mais úteis, do que colocar o indivíduo em uma prisão, local em que poderá ser aliciado por criminosos e organizações criminosas, vindo a cometer muitos outros crimes e com maior gravidade, quando de sua liberdade.

Dessa forma, generalizar um entendimento, seja a favor ou contra a prisão após condenação em Segunda Instância não apenas não resolve o problema, como pode criar muitos outros, como a obrigatoriedade de manter indivíduos presos, em péssimas condições, mesmo diante do cometimento de crimes muitas vezes irrisórios, e, por outro lado, manter em liberdade indivíduos que representam grande ameaça para a sociedade, que podem continuar cometendo crimes, enquanto não ocorre a decisão final em seu caso.

Por fim, entendemos que a decisão do STF é inconstitucional, uma vez que gera insegurança jurídica e tem feito com que o assunto não possua margem para interpretação. Fixar um posicionamento a respeito de um assunto tão polêmico não resolve o problema, uma vez que tais posicionamentos precisam ser capazes de orientar os magistrados em suas decisões e não apenas impor uma situação, que pode não ser aplicável a todos os casos. 
Concordamos com um dos fundamentos do HC 126.292, acerca da questão envolvendo a presunção de inocência seja um princípio constitucional e, como tal, possa ser relativizado, a partir da aplicação ao caso concreto.

Portanto, o STF, em situações como a analisada no presente estudo deve ser capaz de orientar entendimentos e magistrados e não simplesmente criar um entendimento que deve ser aplicado ser margem para adaptações, até mesmo porque, nos últimos dez anos a temática foi alterada três vezes, o que, por si só coloca em dúvida a imparcialidade do Tribunal.

\section{REFERÊNCIAS}

ALEXY, Robert. Teoria dos direitos fundamentais. 2. ed. São Paulo: Malheiros, 2015. Tradução de Virgílio Afonso da Silva.

BOFF, S. A federação como cláusula pétrea. Revista Direito em Debate, v. 11, n. 16-17, 9 mar. 2013.

BRASIL. Supremo Tribunal Federal. ADI 293 MC, Relator (a): Min. Celso de Mello, Tribunal Pleno, julgado em 06/06/1990, DJ 16-04-1993 PP-06429 EMENT VOL-01699-01 PP-00009. Disponível em: <https://www.stf.jusbrasil.com.br/jurisprudencia/2907836/medida- cautelar-na-acao-direta-deinconstitucionalidade-adi-mc-293-pdf >. Acessado 22 nov. 2018.

BRASIL. Presidente da República, Lei n. 9.868, de 10 de novembro de 1999. Dispõe sobre o processo e julgamento da ação direta de inconstitucionalidade e da ação declaratória de constitucionalidade perante o Supremo Tribunal Federal. Brasília, 10 de novembro de 1999; 1780 da Independência e $111^{\circ}$ da República. Disponível em: http://www.planalto.gov.br/ccivil_03/leis/l9868.htm. Acesso em: 18 maio 2019.

BRASIL. Supremo Tribunal Federal. ADI 3.345 MC, Relator (a): Min. Celso de Mello, Tribunal Pleno, julgado em 25/08/2005, DJe 20/08/2010 PP-06429. Disponível em: http://www.stf.jus.br/imprensa/ pdf/adi3345.pdf. Acesso em: 20 maio 2019.

BRASIL. Supremo Tribunal Federal, HC 84.078, Min. Cezar Peloso. Julgado: 05/02/2009. Disponível em: http://www.stf.jus.br/arquivo/cms/noticiaNoticiaStf/anexo/ementa84078.pdf. Acesso em: 22 nov. 2018.

BRASIL. Supremo Tribunal Federal. HC 84.078, Rel. Min. Eros Grau. Julgado: 05/02/2009. Disponível em: http://www.stf.jus.br/arquivo/cms/noticiaNoticiaStf/anexo/ementa84078.pdf. Acesso em: 22 nov. 2018.

BRASIL. Supremo Tribunal Federal. HC 126.292/SP, Relator Min. Teori Zavascky. J.17.02.2016. Disponível em: http://redir.stf.jus.br/paginadorpub/paginador.jsp?docTP=TP\&doclD=10964246. Acesso em: 22 maio 2019. 
BRASIL. Vade Mecum. 23. ed. São Paulo: Saraiva 2017.

BRASIL. STF. Supremo garante a condenado o direito de recorrer em liberdade. Disponível em:

http://www.stf.jus.br/portal/cms/verNoticiaDetalhe.asp?idConteudo=102869. Acesso em: 5 jan. 2020.

BULOS, Uadi Lammêgo. Dez anos de constituição: em torno das cláusulas de inamovibilidade. Rio de Janeiro, 1999.

COSTA, A.; CARVALHO, A.; FARIAS, F.; Controle de constitucionalidade no Brasil: eficácia das políticas de concentração e seletividade. Revista Direito GV, São Paulo, v. 12, n. 1, 2016. Disponível em: https://www. passeidireto.com/arquivo/40812583/controle-de-constitucionalidade-no-brasil. Acesso em: 22 maio 2019.

\section{CONSULTOR JURÍDICO. Com presunção de culpa STF pode antecipar 50 mil prisões por ano.}

Disponível em: http://www.conjur.com.br/2016-out-05/presuncao-culpa-stf-antecipar-50-milprisoes-ano. Acesso em: 20 maio 2019.

DECLARAÇÃo dos Direitos do Homem e do Cidadão (França, 26.08.1789). In: Textos Básicos sobre Derechos Humanos. Madrid, Universidad Complutense, 1973. Traduzido do espanhol por Marcus Cláudio Acqua Viva.

DECLARAÇÃO Universal dos Direitos Humanos. Assembleia Geral das Nações Unidas em Paris. 10 dez. 1948. Disponível em: https://nacoesunidas.org/wp-content/uploads/2018/10/DUDH.pdf. Acesso em: 18 maio 2019.

DWORKIN, Ronald. Levando os direitos a sério. 2. ed. São Paulo: Martins Fontes, 2007. Tradução de Nelson Boeira.

FERREIRA FILHO, Manoel G. et al. Liberdades Públicas. São Paulo: Ed. Saraiva, 1978. Disponível em: http://www.direitoshumanos.usp.br/index.php/Documentos-anteriores-\%C3\%A0cria\%C3\%A7\%C3\%A30-da-Sociedade-das-Na\%C3\%A7\%C3\%B5es-at\%C3\%A9-1919/declaracaode-direitos-do-homem-e-do-cidadao-1789.html. Acesso em: 20 maio 2019.

GOOGLE DICIONÁRIO ONLINE. Presunção. Disponível em: https://www.google.com/search?q=Dicio n\%C3\%A1rio\#dobs=presun\%C3\%A7\%C3\%A3o. Acesso em: 20 maio 2019.

LENZA, Pedro. Direito constitucional esquematizado. 19. ed. São Paulo: RT, 2015.

MIGALHAS. STF volta a proibir prisão em $2^{\mathbf{a}}$ instância: placar foi 6 a 5. Disponível em: https://www. migalhas.com.br/Quentes/17,MI314723,21048-STF+volta+a+proibir+prisao+em+2+instancia+placa $\mathrm{r}+$ foi $+6+a+5$. Acesso em: 8 jan. 2020. 
MINAS GERAIS. Tribunal de Justiça. Ação Cautelar n. 11.0000.00.190354-1/000(1). Relator: Célio César Paduani. Minas Gerais, 16/11/2000, publicação da súmula 06/02/2001. Disponível em: https://tj-mg.jusbrasil.com.br/jurisprudencia/4548636/1903541-mg-1000000190354-1-000-1/ inteiro-teor-11275035?ref=juris-tabs. Acesso em: 15 maio 2019.

MINAS GERAIS. Tribunal de Justiça. Agravo de instrumento n. 1.0701.07.191519-6/001. Agravantes: ALAN LAIO CARDOSO DOS SANTOS. Agravados:

MINISTÉRIO PÚBLICO DO ESTADO DE MINAS GERAIS. Relator: Alberto Vilas Boas. Minas Gerais, 14/08/2007, publicação da súmula 14/08/2007. Disponível em: https://www5.tjmg.jus.br/ jurisprudencia/pesquisaNumeroCNJEspelhoAcordao.do;jsessionid=6BA73A23FB85321509A50 1086F95AB56.juri_node2?numeroRegistro=1\&total Linhas=1\&linhasPorPagina=10\&numeroUni $\mathrm{co}=1.0701 .07 .191519-6 \% 2 \mathrm{F001}$ \&pesquisaNumeroCNJ=Pesquisar. Acesso em: 15 maio 2019. 
1 Bacharel em Direito - UniRV.

E-mail: nicollerodriguesdesouza@gmail.com

2 Mestre em Direito - Univem; Bacharel em Direito - UFMS;

Professora Adjunto I - UniRV; Advogada.

E-mail: Caroline.camargo@unirv.edu.br

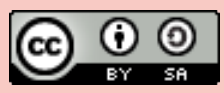

Este artigo é licenciado na modalidade acesso abertosob a Atribuição-Compartilhalgual CC BY-SA

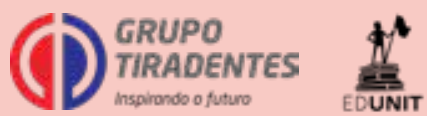

